\title{
Exploration of the Influential Factors on Adherence to Occupational Therapy in Parents of Children with Cerebral Palsy: A Qualitative Study
}

This article was published in the following Dove Press journal: Patient Preference and Adherence

\section{Leeba Rezaie (D) \\ Sadiqa Kendi ${ }^{2}$}

'Sleep Disorders Research Center, Kermanshah University of Medical Sciences, Kermanshah, Iran; ${ }^{2}$ Division of Emergency Medicine, Children's National Health System, Washington DC, PA 200I0, USA
Correspondence: Leeba Rezaie Sleep Disorders Research Center, Farabi Hospital, Kermanshah University of Medical Sciences, Dovlat Abad Blvd, Kermanshah, Iran

Tel +989|8833644I4

Fax +988338264255

Email rezaie.phd.ot@gmail.com
Background: Cerebral palsy (CP) is the leading cause of permanent disability in children. Occupational therapists serve a primary role in the rehabilitation of children with CP. Poor adherence to treatment is common. The aim of this study is to explore the viewpoint of occupational therapists on factors which impact adherence to occupational therapy (OT) interventions among parents of children with CP.

Material and Methods: A qualitative approach using semi-structured interviews were employed. Our participants were recruited by purposive sampling among occupational therapists who were working in Kermanshah province, western Iran. The interviews were taped and transcribed. Content analysis using constant comparison was performed.

Results: The mean age of our participants was $34.23 \pm 7.50$. Four main categories with specific subcategories emerged as important in affecting adherence. The first category of child and family-related factors described factors such as the clinical status of the child and family composition. These factors had the potential for both improving and reducing adherence to treatment. The second category of therapist-related factors described the effect of appropriate professional skills of the therapist on improving adherence and included clinical competency, communication skills, and job satisfaction. The third category of environmental factors addressed factors such as cultural views of child disability and access to OT interventions. The category mostly emphasized environmental barriers to adherence to treatment. The fourth category of therapy-related factors described barriers such as the type of therapy, and the length of treatment.

Conclusion: Adherence to OT interventions in parents of children with $\mathrm{CP}$ can be influenced by several factors. These factors range from child and family-related factors to therapy-related factors and have the potential for both positively and negatively affecting adherence. Programs to improve adherence should address these factors together.

Keywords: cerebral palsy, occupational therapy, adherence, qualitative study, Iran

\section{Introduction}

Cerebral palsy (CP) is a non-progressive encephalopathy resulting from lesions in the developmental brain. It is the main cause of permanent disability in children. ${ }^{1}$ The estimated prevalence of CP is $2 / 1000$ in the general population. It is associated with limitations in movement, posture, and abnormalities in speech, vision, and intellectual abilities ${ }^{2,3}$ which may inhibit the child's normal growth and development and his/her participation in age-related activities. ${ }^{4}$ Symptoms of motor disorders in children with CP include spasticity, muscle contracture, lack of 
coordination, loss of motor control and poor voluntary movements. ${ }^{5}$ In addition, these patients often experience disturbances in sensation, perception, cognition, communication, and behavior. ${ }^{4} \mathrm{CP}$ is a chronic, debilitating condition which requires long-term rehabilitation. ${ }^{5}$

Occupational therapy (OT) is one of the rehabilitation disciplines that work with children with CP. Different approaches are utilized, including neurodevelopmental, and sensory integration. The objective of OT in children with CP is to work with the child to improve the skills necessary for activities of daily living. Occupational therapists focus on several areas in their interventions, including play, self-care (such as feeding, dressing, and grooming), fine motor skills such as writing, cognitive, and visual-spatial problems. Therapy in these areas leads to increased quality of life, and social participation. ${ }^{6,7}$

Parents can play an important role in the rehabilitation process of these children and are an important factor in facilitating the process of therapy. Parent-centered care is an important approach in the care of children with $\mathrm{CP}^{8}$ and adherence significantly impacts the ability to obtain an optimal outcome. Adherence is defined as "the extent to which a person's behavior corresponds with agreed recommendations from a healthcare provider". 9 Adherence can be measured in many ways, including appointment attendance, following treatment recommendations, appointment frequency, maintenance of prescribed home programs, and the level of participation of the parent or caregiver in treatment. ${ }^{10}$ Poor adherence is directly associated with poor treatment outcomes. ${ }^{11}$ Therefore, adherence of parents with CP children is considered to be the primary determinant in the effectiveness of treatment.

Previous studies have reported influential factors on adherence. Rosenbaum and Steward (2006) reported that financial constraints, lack of progress in the condition, and distance the patient have to travel to seek treatment are among influential factors affecting adherence. ${ }^{12}$ Another factor which may be a barrier to adherence is the parent-therapist interaction. Studies show that regular interactions between parents and therapists can lead to better adherence. In addition, therapists who are emotionally supportive, provide reassurance, and work with patients as an equal partner can improve adherence. ${ }^{13,14}$ In contrast, unpleasant experiences of parents with therapists can hinder the treatment process. ${ }^{15}$ Exploring these factors more in-depth with qualitative techniques may inform interventions to improve adherence to treatment.

In Iran, the setting for this study, OT is considered the main effective treatment for children with CP. Occupational therapists have the duty of delivering treatment for these children in concordance with other members of the rehabilitation team, including physiotherapists and speech therapists. OT interventions are delivered in both governmental settings and private offices. The training of therapists varies, with minimum training of a bachelor's degree of OT. Referral of children with CP is usually conducted by physicians (mainly podiatrists and neurologists) or other members of the rehabilitation team. To the best of our knowledge, there is no standard method of assessment for predictors of adherence in parents of children with CP. Our objective in this qualitative study is to explore, from the perspective of the OT, influential factors on adherence to OT treatment in parents with children with $\mathrm{CP}$.

\section{Materials and Methods}

\section{Study Design}

We used a qualitative approach using latent content analysis. Data were collected directly from participants without any previous hypotheses (as is standard in qualitative research). Codes and categories were derived by the inductive process, and conceptually ordered considering properties and dimensions. ${ }^{16,17}$

\section{Setting and Participants}

The study was conducted in the Occupational Therapy Ward of Farabi Teaching Hospital in the central city of Kermanshah province (located in western Iran). Our participants were recruited by purposeful sampling among occupational therapists who were working in Kermanshah. The list of therapists was provided from the Kermanshah Occupational Therapy Association. The inclusion criteria included the willingness to consent to participation in this study, and having at least 5 years' experience in working with children with CP. Occupational therapists working as administrators in the health system were excluded. All eligible therapists were contacted by telephone by a staff member and were asked to set a time to participate in an interview after consent was obtained. In general, the time of each interview was determined by the study participant.

The ethical committee of Kermanshah University of Medical Sciences, Kermanshah, Iran, approved the study. All eligible participants were informed about study protocol and signed informed consent.

\section{Data Collection}

We used semi-structured interview for data gathering. An interview guide was used (Box 1), and served as a loose framework of questions to be asked. The 


\section{Box I Interview Guide}

- Please tell us about your experience in working with children with cerebral palsy.

- Please describe your experiences with adherence to the treatment of parents of children with cerebral palsy.

- In your opinion, what is the importance of adherence to treatment in these parents?

- In your opinion, what factors can influence adherence in these parents?

- In your opinion, how can these factors be managed to improve adherence?

interviews were conducted in the quiet room of the Occupational Therapy Ward of Farabi hospital. All interviews were taped and lasted 20-60 mins. In addition to the taped records of the interview, field notes were written for use as complementary data to the interview transcriptions.

\section{Data Analysis}

Data analysis followed the multi step method proposed by Graneheim and Lundman. ${ }^{18}$ First, taped interviews were transcribed verbatim and prepared for content analysis. In the second stage, before the beginning of coding, the transcribed text was read several times for familiarization. A design for generating codes and categories was considered in the third stage. Codes and categories were extracted by the inductive process through open coding. Text was read line by line and the relevant code(s) identified. The fourth stage included differentiation of categories by constant comparison. A consensus in coding was reached in the fifth stage through peer check, member check and constant comparison. After completing coding and assuring its accuracy, concepts were identified in the sixth stage.

To ensure the trustworthiness and rigor of the data analysis, prolonged engagement with the data, peer check, member check, and external check were used as key strategies in the study. ${ }^{17}$ The transcripts and the extracted codes were reviewed several times and the research team debated the results of the data analysis during its weekly meetings. In addition, 7 participants reviewed the transcripts and analyses and provided feedback. The research data and their analyses were also distributed to another qualitative researcher not involved in data gathering, for external critical evaluation.
Table I Participant Demographic Characteristics

\begin{tabular}{|l|l|}
\hline Variable & N (\%) \\
\hline Age & $34.23(\mathrm{M} ; \mathrm{SD}=7.50)$ \\
\hline Years of experience & $9.94(\mathrm{M} ; \mathrm{SD}=7.02)$ \\
\hline Gender & \\
Male & $8(47.05)$ \\
Female & $9(52.94)$ \\
\hline Education & \\
Bachelor & $8(47.05)$ \\
Master of Science & $9(52.94)$ \\
\hline Work setting & \\
Private office & $8(47.05)$ \\
Governmental setting & $3(17.64)$ \\
Both & $6(35.29)$ \\
\hline
\end{tabular}

Abbreviations: M, Mean; SD, standard deviation.

\section{Results}

We interviewed 17 occupational therapists ( 8 male and 9 female) from September 2018 to December 2018. Some demographic characteristics of the participants are listed in Table 1 .

Four main categories were extracted during data analysis: child and family-related factors (rated by 15 participants), therapist-related factors (rated by all 17 participants), environmental factors (rated by 12

Table 2 Extracted Subcategories, and Categories

\begin{tabular}{|c|c|}
\hline Categories & Subcategories \\
\hline $\begin{array}{l}\text { Child and family related } \\
\text { factors }\end{array}$ & $\begin{array}{l}\text { - Severity of problem } \\
\text { - Shild behavior status } \\
\text { - Stacioeconomic class \& Educational } \\
\text { - Family structure } \\
\text { - Family emotional atmosphere } \\
\text { - Family's previous experience }\end{array}$ \\
\hline Therapist related factors & $\begin{array}{l}\text { - Clinical competency } \\
\text { - Communication skills } \\
\text { - Job satisfaction }\end{array}$ \\
\hline Environmental factors & $\begin{array}{l}\text { - Cultural view } \\
\text { - Physician's awareness } \\
\text { - Physical environment } \\
\text { - Access to OT setting } \\
\text { - Presence of insurance coverage }\end{array}$ \\
\hline Therapy related factors & $\begin{array}{l}\text { - } \text { Assessment tools } \\
\text { - Type of intervention(s) } \\
\text { - Length of treatment }\end{array}$ \\
\hline
\end{tabular}


participants), and therapy-related factors (rated by 8 participants). Each primary category was comprised of multiple related, yet distinct subcategories, which were comprised of particular codes. Table 2 presents the categories and subcategories identified. The following sections describe in further detail each category and their components.

\section{Child and Family-Related Factors}

Our results show that there are features of the child and family that may affect adherence to treatment. This category has six subcategories that are described below.

\section{The Severity of the Child's Problems}

Our Participants believe that the severity of the child's disability is an influential factor on the adherence. They described that children with a higher severity were less likely to respond to treatment, leading to family disappointment and less likelihood to be cooperative. One participant said:

I think the severity of the disorder is very important. Children with fewer problems are more likely to respond to treatment sooner and families are more likely to be encouraged to see their child changes in their treatment sessions and at work at home. (p11)

\section{Child Behavioral Status}

Participants stated that the child's behavioral status (such as temper tantrums) is an important factor which affects the parent's ability to work with him or her in the home. One participant said:

Sometimes the family tells me with sadness that the child does not do any homework at home, and when they want to repeat the exercises at home, he/she begins to cry and mutter, so the parent is forced to abandon the exercise. (p2)

\section{Socioeconomic Class and Education Status}

Participants also stated that the socioeconomic class of the family was one of the most influential factors in adherence to treatment. Families with a higher socioeconomic level are more cooperative than those who come from a lower level. One participant said:

My clinical experience has shown that families should be divided into two categories: families with a high level of social well-being, and families with a low level of social well-being. Families with higher levels are more cooperative and have a better understanding of their role in treatment. Even these families sometimes do not have another child to have more participation in the treatment. (p3)

\section{Family Structure}

Participants stated that the family structure, including presence or absence of extended family can affect adherence to treatment. They expressed both negative and positive influence of the family structure.

One participant said:

Intrusiveness of the surrounding people is very effective in parent adherence. I have worked some parents who have had the high motivation to cooperate in treatment, but have complained about the intrusiveness of others. One of them told me that my mother very much interfered with bringing my daughter to OT session. She believes it is futile and says that you are wasting your money. This baby is not good. (p 1)

Another participant said:

The presence of other family members such as aunts and uncles, grandparents or even older children can be very helpful. They can take part in care of the child and increase the possibility of adherence to treatment. In fact, they can support the family. (p5)

\section{Family Emotional Atmosphere}

Participants believe that if the parents of the child had an appropriate emotional relationship, they would be better off coping with the child's problem of treatment, and vice versa. One participant said:

Sometimes we see that parents are disagreed with each other to bring the child to OT clinic, the mother likes to bring the child, but the father is opposed. Of course, in my opinion, these conflicts already existed and are now exacerbated by having a child with CP. (p8)

\section{Family's Previous Experiences}

The family's previous experience with treatment was also considered as an influential factor in treatment adherence. One participant said:

I think it is very important to know what advice the previous therapist has given. Sometimes I encounter with families that they are surprised to tell me if we need to repeat the exercises at home because the previous therapist did not tell us. Some therapists sometimes even scare the 
family from repeating exercise at home. I do not know why. (p3)

\section{Therapist Related Factors}

The second extracted category was therapist related factors, with three specific sub-categories including therapist's clinical competency, therapist's communication skills and therapist's job satisfaction. We describe them below:

\section{Clinical Competency}

Study participants believe that the clinical competency of the therapist, which includes adequate and up-to-date knowledge and experience regarding treatment, accurate evaluations, proper planning, and case management, are all factors which affect adherence to treatment. One participant said:

The role of occupational therapist is very important. It is actually a therapist who supports the family in the treatment process. The therapist should have an accurate assessment of the child's condition, determine the goals of treatment tailored to the child's circumstances, and provide clear and understandable advice on the child's situation to the family.(p 6)

\section{Therapist Communication Skills}

Based on the interviews, skills such as empathy, patience, and trustworthiness lead to proper communication with the child, and the family can be effective in increasing adherence to therapy. One participant said:

I think the therapist's relationship is very important; the therapist should be able to draw the family's confidence in the treatment. Increase their motivation. Establish a friendly relationship with them. The therapist should be patient to advise the family and help them to cope with the child. (p12)

\section{Job Satisfaction}

Study participants believe that if the therapist was happy with his or her work and income, he or she would enjoy working with the patient, and have a higher incentive to work with their families, making him/her more likely to be successful in motivating them to follow-up for treatment. One participant said:

OT is a hard job. He receives little salary in exchange for the work he carries out.Interest to work is very important. In my opinion, occupational therapists who choose this field of interest and who work in their own private clinics who earn more, are more motivated and are more inclined to increase adherence of. (p17)

\section{Environmental Factors}

Environmental factors were another category extracted in this study. Participants believed that many environmental factors could affect the families' adherence as described below:

\section{Cultural View}

Participants believed that disability is not accepted in some cultures, and many families have difficulty accepting their child's problems and treating them. One participant said:

Culturally, especially in rural areas, disability is associated with stigma, and families are concealing the disability of their child and therefore do not collaborate in the treatment and continuation of treatment. (p13)

\section{Physicians' Awareness}

Participants in this study believed that physicians' awareness about occupational therapy and their emphasis on families about the importance of occupational therapy interventions can impact family adherence. One participant said:

I think doctors have a very important role, especially at the beginning of treatment. I have experienced when the doctor emphasizes the families; they aremore cooperative. Unfortunately, many doctors do not yet familiar with OT. (p14)

\section{Physical Environment}

Participants also believed that the physical environment of the OT clinic, including equipment and facilities, can be an important factor in building family trust and increasing adherence to treatment. One participant said:

The appearance of the clinic is important. Clinic cleanliness is important. The equipment must be adequate and appropriate. Clinic should be in a good condition in terms of light and temperature. Relaxing music is good to enjoy, and having a simple meal like a biscuit for the family is also good, so that the family can withstand the waiting times in the clinic and will be willing to attend medical sessions. (p12) 


\section{Access to Occupational Therapy}

Easy access and short distance to the OT clinic were identified as important in adherence to treatment. One participant said:

We actually see that families from other cities who need to travel for a long distance are subject to have poor adherence. On the other hand, when several rehabilitation clinics such as speech therapy, physiotherapy and occupational therapy are in place, the time and money of the family is saved.It result in better adherence in the family. (p9)

\section{Insurance Coverage}

Participants believed that the lack of insurance coverage for occupational therapy services contributes to poor adherence. One participant said:

Children with cerebral palsy need long-term treatment. Occupational therapy interventions are not covered by insurance. It is a strong reason for poor adherence of the families. Actually, we see that the family decrease 3 times in week to 1 time in week due to lack of insurance coverage. (p2)

\section{Therapy Related Factors}

The nature of occupational therapy and its interventions are important in family adherence. This category has three subcategories: assessment tools, type of interventions, and length of treatment. We describe them below:

\section{Assessment Tools}

Participants also believed that the tool for assessment is a factor in adherence to treatment since it can help the therapist to describe the status of the child and his or her progress in treatment to the family. It also can be helpful for writing a progress note for physicians. One participant said:

One of the problems with CP field is assessment tool. We do not have a precise assessment tool that we periodically evaluate and report on therapeutic changes to the family or doctor, I think this will affect adherence to treatment. (p8)

\section{Type of Intervention}

Participants believed that families did not have a positive attitude towards occupation-based treatment such as play, and they had poorer cooperation. One participant said:

When the therapist tries to work by occupation - based approach, The families are not happy with the treatment, and they say that they can play with their children themselves. But they have a positive attitude toward exercise therapy and follow them in home. (p9)

\section{Length of Treatment}

Participants believed that because occupational therapy is a long-term treatment that requires significant free time and cost over time, treatment adherence in the families is poor. One participant said:

Occupational therapy is not user friendly treatment. Too long. Families should bring the children for several years. It requires time and cost. Adherence may be good in the early stages of the treatment, but it will weaken over time. (p 10)

\section{Discussion}

The present study was conducted to explore the perspective of occupational therapists on factors influencing adherence to therapy in parents of children with $\mathrm{CP}$ in Iran. The four main categories of child and familyrelated factors, therapist related factors, environmental factors, and therapy-related factors were extracted from participants' statements. These findings concur with results of other studies conducted on this subject ${ }^{12-15}$ and provide clinically useful information. In particular, the category of child and family-related factors highlights the direct effect that the status of both the child and family has on adherence to occupational interventions. Within this category, severity of the child's clinical condition secondary to $\mathrm{CP}$ was considered an influential factor. Since more severe problems are usually associated with a lesser likelihood of improvement, the parents have less motivation for adherence to treatment. As recommended by Lord et al (2018), motivational interviewing can be helpful to increase motivation for parent engagement in treatment. ${ }^{19}$ The technique of motivational interviewing is defined as "a collaborative conversation style for strengthening a person's own motivation and commitment to change". ${ }^{20}$ In addition, it is important for occupational therapists to assist the parents in goal setting, with reasonable expectations of treatment outcome.

Child behavioral status also emerged as a subcategory for child and family-related factors. Behavioral problems can decrease parents' cooperation in repeating the therapeutic exercise at home. Behavioral problems are common in children with $\mathrm{CP}$ and can predict restricted participation, and reduced quality of life in these children. ${ }^{21}$ As reported by Weber et al (2016), there are many predictive 
factors for behavioral problems among children with $\mathrm{CP}$, including pain intensity, anxiety, parental stress and support, executive function level, better gross motor function, poorer intellect, living in town, and having a disabled/ill sibling. ${ }^{22}$ Therefore, addressing behavioral problems in children with $\mathrm{CP}$ is an important part of addressing adherence.

The family's socioeconomic class can influence adherence to treatment. The role of socioeconomic class in adherence to treatment in other diseases such as diabetes has been reported. ${ }^{23}$ Socioeconomic class, including education, income, and occupation can affect access to treatment. With this in mind, the barrier of low socioeconomic class should be addressed to improve adherence to treatment.

Family structure was another influential factor. According to the results, living with an extended family and in the presence of grandparents, aunts and uncles can have both negative and positive effects on adherence. While the intrusiveness of extended family may inhibit parent adherence, the family can also be very supportive in caring for the child and improving adherence. Therefore, appropriate interventions should be implemented to encourage the positive and reduce the negative effects. Inviting extended family to treatment sessions to encourage their participation in treatment is one of the practical approaches that an occupational therapist can apply.

The emotional atmosphere of the family was also important in adherence to treatment. Parental concordance is an important factor which promotes adherence to treatment. Notably, the presence of a child with a permanent disability may challenge the family dynamics due to stressors such as time constraints, financial consequences, and strained social relationships. ${ }^{24}$ Therefore, the presence of family conflict is an expected reaction, especially at the early stages of diagnosis and treatment and addressing the emotional atmosphere of the family is important. As recommended by Guyard et al (2018), understanding of the broad context of the disability is necessary, and families who are at risk of stress should be the target of interventions. $^{25}$

The last subcategory was the family's previous experience with treatment. The experience of the family with a previous occupational therapist can influence their adherence to treatment. In fact, adherence is often formed from early interactions, and the therapist plays an important role. ${ }^{15}$ Providing families with information about the role they play in treatment can help them to promote adherence to the treatment.

The second category was therapist related factors. The category describes the role that occupational therapist plays in building and improving adherence. Occupational therapists should be able to encourage the clients and their family to actively engage in the treatment. In addition, recently there is a trend towards the role of OTs in improving the adherence of their patients to other treatments, such as medication. ${ }^{26}$ Therefore, it is important that occupational therapists have the necessary skills in this area.

Clinical competency (knowledge and clinical skills) and communication skills (empathy, and patience) were two subcategories of therapist-related factors which influence adherence to treatment. Competence is defined as

The habitual and judicious use of communication, knowledge, technical skills, clinical reasoning, emotions,values, and reflection in daily practice for the benefit of the individual and community being served. ${ }^{27}$

Competence has a pivotal role for health professionals such as physicians, physiotherapists, and occupational therapists. According to the definition, two extracted subcategories (clinical competency and communication skills) are necessary parts of the competency concept. It seems study participants separated communication skills from clinical competency because of its importance. Notably, the American Association of Occupational Therapy (AOTA) has considered 5 standards of knowledge, including clinical reasoning, interpersonal abilities, performance skills, and ethical reasoning for continuing competence of occupational therapists. $^{28}$ Therefore, competency is an important skill for occupational therapists for many reasons including improved adherence to treatment.

The third subcategory of therapist-related factors was job satisfaction. Therapists who have more interest in their profession and higher income have a higher level of job satisfaction and level of motivation to work on family adherence. The role of job satisfaction in treatment outcome has been reported by Mache et al (2012). They reported that there is an association between job satisfaction and quality of medical treatment and patients'

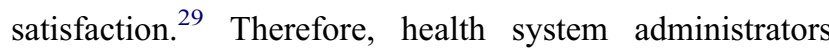
should use strategies including appropriate salary for enhancing job satisfaction of occupational therapists.

The third extracted category described the role of environmental factors in adherence to treatment. In OT conceptual models, including the model of human 
occupation (MOHO), human occupations generate and change in interaction with the environment. In this model, environment can play both a facilitator and an inhibitor role. ${ }^{30}$ Our results also showed the role of environment in parents' adherence to treatment. Cultural views of disability may be associated with stigma which hinder adherence to treatment. Disease - related stigma has been reported as a barrier to seeking treatment and participation in daily activities. ${ }^{31,32}$ Reduction of cultural disability stigma should be a target for intervention. Providing the community with information about cerebral palsy and treatment by mass media can help to reduce stigma and increase positive attitudes towards treatment.

Physician awareness about the OT's role in rehabilitation of children with CP was another extracted subcategory. Physicians have an important role since they are the first for diagnosis and treatment. Therefore, it is important for OT administrators to plan strategies to provide physicians with evidence-based knowledge and awareness about OT. Recently Darawshe (2018) emphasized the importance of interprofessional learning to preserve the identity of OT among other health-care professionals in his report of awareness and knowledge about OT in Jordan. ${ }^{33}$

Another influential factor on adherence identified was the physical environment and equipment in the OT clinic. A comfortable environment can improve adherence to treatment. $^{34}$ Occupational therapists should provide as comfortable an environment as possible for treatment, especially in private clinics.

Access to the OT office or clinic setting was also identified as influential on adherence to treatment. Shorter distance to the office and easy access to other therapists including physiotherapists and speech therapists were mentioned as factors which predicted better adherence. There is no known report about access to treatment for children with CP in Iran. However, Bright et al (2019) reported poor access to rehabilitation services among lowand middle-income countries. ${ }^{35}$ Therefore, access to rehabilitation services including OT services should be addressed as a barrier by health administrators.

Insurance coverage was another influential factor in adherence to treatment. In Iran, the focus of this study, there is very limited insurance coverage for OT interventions. This is a barrier to adherence, especially since OT is a long-term treatment, and children with $\mathrm{CP}$ are usually from low socioeconomic families with limited income to directly pay the cost of OT interventions. Therefore, in addition to health policymakers efforts to expand the coverage of insurance companies, non-governmental organizations (NGO) can also be helpful in providing financial support for these families.

The last extracted category is therapy-related factors, with three subcategories including assessment tools, type of intervention, and length of therapy. Limited assessment tools to provide objective measures of progress for occupational therapists' work in the $\mathrm{CP}$ field can have a negative effect on the family's adherence to treatment. They need to see the outcome of therapy to motivate them to continue therapy, and assessment tools are helpful in identifying and measuring the goal. Therefore, the development and enhanced access to valid assessment tools for occupational therapists would improve the effectiveness of evidence-based rehabilitation techniques, therefore improving adherence.

Type of intervention was another extracted subcategory. Parents' interpretations of simple occupation based interventions such as play may inhibit their desire to continue treatment, since they do not put value in the techniques as therapeutic. In some communities, a medical approach is seen as the dominant approach, however the efficacy of occupation - based interventions in children with CP has been reported in several studies. ${ }^{36,37}$ Providing the parent with information about the type of intervention and how it can be effective in an understandable manner is important.

OT is a long-term treatment that requires parental patience, free time, and financial commitment. All of these requirements can decrease adherence to treatment. ${ }^{33}$ One technique which can be helpful is a therapy holiday. In this technique, the parents can leave treatment temporarily and in concordance with occupational therapists, to allow parents to restore their stamina for continued treatment.

\section{Limitations}

The present study is the first to explore influential factors on adherence to occupational therapy among parents of children with CP. Nonetheless, there are two limitations. First, the research team did not collect information from parents, and other professional teams including physicians about influential factors on adherence to treatment. Secondly, the sample of this study was limited to therapists who were working and did not include faculty or staff in rehabilitation schools, and occupational therapy students. These sources may have identified additional influential factors on adherence to treatments. 


\section{Conclusion and Implications}

Although results cannot be generalized to all parents of children with CP, there are several conclusions and implications from this study. First, the study showed that adherence to treatment is affected by four broad categories of child and family-related factors, therapist-related factors, environmental factors, and therapy-related factors. These factors have the potential to impact adherence positively or negatively. These results can be helpful for planning programs to improve adherence.

The challenge of managing children with $\mathrm{CP}$ and physical and behavioral problems can include specific problems such as family conflicts, economic cost and additional burden of care. On the other hand, the family socioeconomic class, structure, and atmosphere have a direct effect on the child's clinical status. The outcome of the bidirectional effect of child and family is an important influence on adherence to treatment. Therefore, any planning to improve adherence in parents of children with CP should pay specific attention to these bidirectional effects.

Third, therapist related factors including clinical competency, communication skills, and job satisfaction among other factors can be modifiers. In general, OTs have a role in empowering children with $\mathrm{CP}$ and their families to adapt and live with the challenges. Working with families is one of the basic elements of the therapeutic process considered for these children. Thus, the therapist's clinical competency, communication skills, and job satisfaction are associated with improved ability to work with the children, more positive attitudes of the parents toward treatment and preparation for long-term treatment. Identification of a standard for competency of occupational therapists who work with patients with $\mathrm{CP}$ is necessary, and it should be considered as a requirement for getting license of work.

Finally, overcoming potential environmental barriers such as access to OT services, and insurance coverage should be done in coordination with health policymakers including the ministry of health and welfare organizations.

In conclusion, this study identified several influential factors on adherence of parents of children with $\mathrm{CP}$ to occupational therapy interventions. Strategies should be implemented to improve adherence to treatment by encouraging the facilitators and inhibiting the barriers as described.

\section{Acknowledgment}

The authors wish to thank all who participated in this study.

\section{Disclosure}

The authors have no conflicts of interest to disclose.

\section{References}

1. Jones W, Morgan E, Shelton JE, et al. Cerebral Palsy: introduction and diagnosis (Part 1). J Pediatr Health Care. 2007;21(3):146-152. doi:10.1016/j.pedhc.2006.06.007

2. Lin J. The cerebral palsies: a physiological approach. J Neurol Neurosurg Psychiatry. 2003;74(24):23-29. doi:10.1136/jnnp.74. suppl $1 . i 23$

3. Rosenbaum P, Paneth N, Leviton A, Goldstein M, Bax M. A report: the definition and classification of cerebral palsy April 2006. Dev Med Child Neurol Suppl. 2007;109:8-14.

4. Odding E, Roebroeck M, Stam H. The epidemiology of cerebral palsy: incidence, impairments and risk factors. Disabil Rehabil. 2006;28:183-191.

5. Cans C. Surveillance of cerebral palsy in Europe: a collaboration of cerebral palsy surveys and registers. Dev Med Child Neurol. 2000;42 (12):816-824. doi:10.1111/j.1469-8749.2000.tb00695.x

6. DeLisa JA, Gans BM, Bockenek WL. Rehabilitation Medicine: Principles and Practice. Philadelphia: Lippincott-Raven; 1998.

7. Steultjens EM, Dekker J, Bouter LM, van de Nes JC, Lambregts BL, van den Ende $\mathrm{CH}$. Occupational therapy for children with cerebral palsy: a systematic review. ClinRehabil. 2004;18(1):1-14.

8. Hinojosa J, Sproat CT, Mankhetwit S, Anderson J. Shifts in parent-therapist partnerships: twelve years of change. Am J Occup Ther. 2002;56(5):556-563. doi:10.5014/ajot.56.5.556

9. Meyer T, Gutenbrunner C, Bickenbach J, Cieza A, Melvin J, Stucki G. Towards a conceptual description of rehabilitation as a health strategy. J Rehabil Med. 2011;43(9):765-769. doi:10.2340/ 16501977-0865

10. Kolt GS, McEvoy JF. Adherence to rehabilitation in patients with low back pain. Man Ther. 2003;8(2):110-116. doi:10.1016/S1356-689X (02)00156-X

11. Santer M, Ring N, Yardley L, Geraghty AW, Wyke S. Treatment non adherence in pediatric long-term medical conditions: systematic review and synthesis of qualitative studies of caregivers' views. BMC Pediatr. 2014;14:63. doi:10.1186/1471-2431-14-63

12. Rosenbaum P, Stewart D. The World Health Organization International Characteristics of Functioning, Disability and Health: A Model to Guide Clinical Think Practice and Research in the Field of CAP. Seminars in Paediatric Neurology. Geneva: WHO; 2004.

13. Storey PP, Murchison AP, Pizzi LT, et al. Impact of physician communication on diabetic eye examination adherence: results from a retrospective cohort analysis. Retina. 2016;36(1):20-27. doi:10.1097/IAE.0000000000000652

14. Essery R, Geraghty AW, Kirby S, Yardley L. Predictors of adherence to home-based physical therapies: a systematic review. Disabil Rehabil. 2017;39(6):519-534.

15. Carter JA, Molyneux CS, Mbuba CK, Jenkins J, Newton CR, Hartley SD. The reasons for the epilepsy treatment gap in Kilifi, Kenya: using formative research to identify interventions to improve adherence to antiepileptic drugs. Epilepsy Behav. 2012;25 (4):614-621. doi:10.1016/j.yebeh.2012.07.009

16. Strauss A, Corbin J. Basics of Qualitative Research: Techniques and Procedures for Developing Grounded Theory. 2nd ed. Thousand Oaks, USA: Sage Publications; 1998. 
17. Streubert H, Carpenter D. Qualitative Research in Nursing: Advancing the Humanistic Imperative. 4th ed. Philadelphia: Lippincott Williams \& Wilkins; 2007.

18. Graneheim UH, Lundman B. Qualitative content analysis in nursing research: concepts, procedures and measures to achieve trustworthiness. Nurse Educ Today. 2004;24(2):105-112. doi:10.1016/j.nedt.2003.10.001

19. Lord C, Rapley T, Marcroft C, Pearse J, Basu A. Determinants of parent-delivered therapy interventions in children with cerebral palsy: a qualitative synthesis and checklist. Child Care Health Dev. 2018;44 (5):659-669. doi:10.1111/cch.v44.5

20. Miller WR, Rollnick S. Motivational Interviewing: Helping People Change. New York: Guilford Press; 2013.

21. Dang VM, Colver A, Dickinson HO, et al. Predictors of participation of adolescents with cerebral palsy: a Europeanmulti-centre longitudinal study. Res Dev Disabil. 2015;36:551e64.

22. Weber P, Bolli P, Heimgartner N, Merlo P, Zehnder T, Kätterer C. Behavioral and emotional problems in children and adults with cerebral palsy. Eur J Paediatr Neurol. 2016;20(2):270-274. doi:10.1016/j. ejpn.2015.12.003

23. Shams N, Amjad S, Kumar N, Ahmed W, Saleem F. Drug non-adherence in Type 2 diabetes mellitus; predictors and associations. J Ayub Med Coll Abbottabad. 2016;28(2):302-307.

24. Brehaut JC, Kohen DE, Raina P, et al. The health of primary caregivers of children with cerebral palsy: how does it compare with that of other Canadian caregivers? Pediatrics. 2004;114(2):e182-e191. doi:10.1542/peds.114.2.e182

25. Guyard A, Michelsen SI, Arnaud C, Fauconnier J. Family adaptation to cerebral palsy in adolescents: a European multicenter study. ResDevDisabil. 2017;61:138-150.

26. Schwartz JK, Smith RO. Integration of medication management into occupational therapy practice. Am J Occup Ther. 2017;71 (4):7104360010p1-7104360010p7. doi:10.5014/ajot.2017.015032

27. Epstein RM, Hundert EM. Defining and assessing professional competence. J Am Med Assoc. 2002;287:226-235. doi:10.1001/ jama.287.2.226
28. Myers CT, Schaefer N, Coudron A. Continuing competence assessment and maintenance in occupational therapy: scoping review with stakeholder consultation. Aust Occup Ther J. 2017;64(6):486-500.

29. Mache S, Vitzthum K, Klapp BF, Groneberg D. improving quality of medical treatment and care: are surgeons' working conditions and job satisfaction associated to patient satisfaction? Langen Becks Arch Surg. 2012;397(6):973-982. doi:10.1007/s00423-012-0963-3

30. Kielhofner G, Burke JP. A model of human occupation, Part 1. conceptual framework and content. Am J Occup Ther. 1980;34:572-581. doi:10.5014/ajot.34.9.572

31. Rani A, Thomas PT. Stress and perceived stigma among parents of children with epilepsy. Neurol Sci. 2019;40:1363-1370. doi:10.1007/ s10072-019-03822-6

32. Rezaie L, Shafaroodi N, Philips D. The barriers to participation in leisure time physical activities among Iranian women with severe mental illness: a qualitative study. Ment Health Phys Act. 2017;13:171-177. doi:10.1016/j.mhpa.2017.09.008

33. Darawsheh WB. Awareness and knowledge about occupational therapy in Jordan. Occup Ther Int. 2018;2018:2493584.

34. Khazaie H, Rezaie L, Shahdipour N, Weaver P. Exploration of the reasons for dropping out of psychotherapy: a qualitative study. Eval Program Plann. 2016;56:23-30. doi:10.1016/j.evalprogplan.2016.03.002

35. Bright T, Wallace S, Kuper HA. Systematic review of access to rehabilitation for people with disabilities in low- and middle-income countries. Int J Environ Res Public Health. 2018;15 (10). doi:10.3390/ijerph15061188

36. McLean B, Taylor S, Blair E, Valentine J, Carey L, Elliott C. Somatosensory discrimination intervention improves body position sense and motor performance in children with hemiplegic cerebral palsy. Am J Occup Ther. 2017;71(3):7103190060p1-7103190060p9. doi:10.5014/ajot.2016.024968

37. Anderson L, Wilson J, Williams G. Cognitive orientation to daily occupational performance (CO-OP) as group therapy for children living with motor coordination difficulties: an integrated literature review. Aust Occup Ther J. 2017;64(2):170-184.
Patient Preference and Adherence

\section{Publish your work in this journal}

Patient Preference and Adherence is an international, peer-reviewed, open access journal that focusing on the growing importance of patient preference and adherence throughout the therapeutic continuum. Patient satisfaction, acceptability, quality of life, compliance, persistence and their role in developing new therapeutic modalities and compounds to optimize clinical outcomes for existing disease states are major areas of interest for the journal. This journal has been accepted for indexing on PubMed Central. The manuscript management system is completely online and includes a very quick and fair peer-review system, which is all easy to use. Visit http:// www.dovepress.com/testimonials.php to read real quotes from published authors. 